\title{
Wrong place at the wrong time: how retrograde trafficking drives cancer metastasis through receptor mislocalization
}

\author{
Sabrina A. Maisel' ${ }^{1}$, Joyce Schroeder ${ }^{1,2,3}$ \\ 'Department of Molecular and Cellular Biology, University of Arizona, Tucson, AZ 85724, USA. \\ ${ }^{2}$ Arizona Cancer Center, University of Arizona, Tucson, AZ 85724, USA. \\ ${ }^{3}$ BIO5 Institute, Tucson, AZ 85724, USA.
}

Correspondence to: Dr. Joyce Schroeder, Arizona Cancer Center, University of Arizona, 1515 N Campbell Ave 3945A, Tucson, AZ 85724, USA.E-mail: joyces@email.arizona.edu

How to cite this article: Maisel SA, Schroeder J. Wrong place at the wrong time: how retrograde trafficking drives cancer metastasis through receptor mislocalization. J Cancer Metastasis Treat 2019;5:7.

http://dx.doi.org/10.20517/2394-4722.2018.82

Received: 30 Nov 2018 First Decision: 30 Dec 2018 Revised: 1 Jan 2019 Accepted: 4 Jan 2019 Published: 13 Feb 2019

Science Editor:William Schiemann Copy Editor: Cui Yu Production Editor: Huan-Liang Wu

\begin{abstract}
Retrograde trafficking is a well-regulated, multi-component pathway that can result in endosomal trafficking to the trans-Golgi network, the perinuclear space, or the nucleus. Either clathrin or the retromer complex can travel with proteins endocytosed from the plasma membrane, guided by Rabs (including 5, 6, 7, 9, 22A), interacting with a host of sorting nexin proteins, and fusing with Golgi-specific anchors to allow transport of activated receptor tyrosine kinases to a potential end within the nucleus. Amplification in these constituents is common in cancer, leading to increased retrotranslocation and a reduction in degradation of receptor tyrosine kinases, an event highly associated with cancer metastasis. Here, we review the role of retrograde trafficking in altering transmembrane receptor localization and activity and the relationship to metastasis, focusing on all four members of the ErbB family, with comparison to other receptor tyrosine kinases including the insulin receptor and fibroblast growth factor receptor, as well as other transmembrane proteins dysregulated in metastasis. By examining how these receptors are being alternatively trafficked and the cancer-associated events resulting from this process, we hope to identify novel therapeutic targets.
\end{abstract}

Keywords: Retrograde trafficking, receptor tyrosine kinase, metastasis, nuclear receptor 


\section{INTRODUCTION}

Retrograde transport is a process that involves secretory trafficking pathways from endosomes to the transGolgi network (TGN), the Golgi to the endoplasmic reticulum (ER), and within the perinuclear space, designed to maintain a steady-state localization of proteins ${ }^{[1-4]}$. Upon internalization of a receptor, toxin, or other constituent subject to intracellular trafficking, cargo is transported to the early endosomes. There, cargo can be recycled to the plasma membrane (with or without passing through the recycling endosome), transferred to a late endosome en route to the lysosome for degradation, or subject to retrotranslocation to the trans-Golgi ${ }^{[5]}$. Within the Golgi proteins can undergo post-translational modifications, be distributed to their appropriate cellular localization (e.g., polarized membrane), or sent to the ER for re-folding or ERassisted degradation (ERAD). In this review, we focus on retrograde trafficking, not for the purposes of protein homeostasis, but rather examining how activated receptor tyrosine kinases are trafficked towards the nucleus upon internalization, where a host of signal transduction, DNA binding, and transcription result in metastatic events. In multiple kinase receptor families, including the ErbB family, this alternative trafficking results in endosomally-captured active receptors in the perinuclear space and nucleus. This trend is not specific to solely receptor tyrosine kinases, as we also discuss the retrotranslocation of other transmembrane proteins, such as the interleukin-2 receptor (ILR2) and the transforming growth factor $\beta$ (TGF- $\beta$ ) receptor. In addition to perinuclear localization, retrotranslocation is frequently associated with the upregulation and constitutive activation of the phosphatidylinositol-3-OH kinase (PI3K)/protein kinase B (AKT) pathways, known drivers of cancer metastasis. Taken together, we present the concept that retrotranslocation of activated proteins, particularly receptor tyrosine kinases, augments AKT signaling and increases nuclear transcription, resulting in cancer metastasis.

\section{MEDIATORS OF RETROTRANSLOCATION Internalization}

Internalization of cargo, the first conserved step of retrograde trafficking (receptor tyrosine kinases require activation, toxins do not) occurs in two primary formats - clathrin-mediated endocytosis (CME) or retromer-assisted. Toxins (such as shiga, ricin, or cholera) and many receptor tyrosine kinases are subject to retrotranslocation from the early endosome in clathrin-coated endosomes, while transmembrane receptors such as wntless, $\beta$-secretase (BACE1), and TGN38 interact with the retromer complex from the early endosome ${ }^{[6-11]}$. Trafficking constituents such as mannose 6 phosphate receptor and Vsp10 are directed from late endosomes via the retromer complex ${ }^{[12-14]}$.

CME occurs when clathrin triskelions form a bilayered coat of polyhedral lattices surrounding an inner coat of clathrin adaptors. Adaptors are then responsible for interacting with the cytoplasmic domains of membrane-bound receptors, and in some instances, even appear to promote the binding of clathrin directly to the receptor ${ }^{[15]}$. Clathrin can interact not only with the cytoplasmic domain of receptors, but also with post-translational modifications, and at the interface between endosomes and the $\mathrm{TGN}^{[3,16]}$. It has been demonstrated that clathrin is frequently required for retrograde trafficking, both for endogenous cargo and plasma-membrane-localized proteins ${ }^{[3,17]}$.

\section{The retromer}

In contrast to clathrin-mediated retrotranslocation, proteins can also be trafficked via the retromer complex. The retromer is a three-protein complex consisting of Vsp26, 29, and 35, capable of binding the cytoplasmic domain of transmembrane proteins located in endosomes without interacting with clathrin. Once bound, the retromer interacts with a dimer of sorting nexin (SNX) family members (either SNX1/2 and SNX5/6) to induce membrane curvature and direct retrograde trafficking away from lysosomal degradation ${ }^{[1,18]}$. This trimer interacts with GTPases; Rab5 when interacting with the early endosome or Rab7 with the late endosome ${ }^{[2]}$. SNX proteins directly interact with the membrane, with a Bis/amphihysin/Rvs domain to sense 
and stabilize membrane curvature and a PX domain capable of interacting with phosphoinositides (PtdIns) to determine the localization of early endosomes ${ }^{[18-20]}$. Alteration of SNX proteins can directly affect receptor tyrosine kinase activity, as loss of SNX1 activity is correlated to a reduction in lysosomal degradation of epidermal growth factor receptor $(\mathrm{EGFR})^{[21-23]}$.

\section{Rab GTPases and retrotranslocation}

Whether cargo enters the system via CME or SNXs, it will be found associated with Rab GTPases. The Rab family of proteins - highly specialized in location and function, are frequently amplified but not mutated in metastatic cancers, leading to increased availability of retrograde trafficking vesicle fusion components, thereby promoting unabrogated receptor signal transduction and uninhibited nuclear colocalization ${ }^{[24-27]}$.

Rab proteins are GTPases involved in vesicular transport, providing membrane identity and tethering vesicles prior to fusion ${ }^{[26,28]}$. They are capable of interacting with other coat components, motor proteins including kinesins and myosins, and soluble $\mathrm{N}$-ethylmaleimide-sensitive factor attachment protein receptors (SNAREs) $^{[26]}$. Despite strong homology among the family members, each Rab confers a unique function to the vesicles they mediate in response to specific activators ${ }^{[29]}$. Two Rabs in particular are known mediators of retrotranslocation: Rab22A which acts in early endosome-TGN trafficking, and Rab6A which is involved in Golgi-ER transport.

Rab22 A is involved in clathrin-independent endocytosis, associating with both early and late endosomes, but not lysosomes. When bound to GTP and active, Rab22A is capable of binding to early endosome antigen 1 (EEA1; a marker unique to the endosomal sorting complex where most transmembrane receptors pass through during endocytosis), directing the activator for Rab5 to promote early endosome fusion, a necessary step in retrotranslocation ${ }^{[30]}$. Rab22A expression is increased in lung, liver, ovarian, renal cell carcinoma, and melanoma ${ }^{[30,31]}$. Rab22A is also commonly overexpressed in breast cancer and associated with decreased patient survival. A HIF1 $\alpha$-dependent Rab, Rab22A is responsible for generating hypoxia-induced vesicles, that when present promote breast cancer cell invasion through cytoskeletal alterations ${ }^{[32]}$. Using miRNAs to suppress the expression of Rab22A, studies have demonstrated that miR-373 can inhibit ovarian cancer, miR-203 inhibits osteosarcoma, and miR-204 inhibits renal cell carcinomas, all in a Rab22A-dependent manner ${ }^{[31,33,34]}$.

Rab6A is a GTPase associated with highly dynamic vesicles subject to retrograde transport from the Golgi to the $\mathrm{ER}^{[35]}$. Part of the recycling endocytic pathway, Rab6A is known to function within the cis- and transGolgi, involved in both intra-Golgi and coat protein complex-1 (COP-1)-mediated Golgi-ER transport ${ }^{[36-38]}$. Frequently dysregulated and associated with poor prognosis in cancer, it also presents with increased expression in human epidermal growth factor 2 (HER2+; ErbB2) breast cancer patients ${ }^{[35,39]}$.

One of the primary functions of the Golgi is to aid in post-translational modifications (such as glycosylation) of proteins, particularly for activation of receptor tyrosine kinases, which allows for ligand binding, receptor trafficking, and internalization ${ }^{[40]}$. As previously discussed, a key element of retrotranslocation is the ability of vesicles to fuse with the TGN, instead of trafficking for lysosomal degradation. GOLPH3, a resident Golgi protein, localizes to the TGN and can directly interact with the retromer complex through Vsp35. Responsible for driving cell proliferation, tumor development, and anchorage independent growth both in vitro and in vivo, GOLPH3 is an oncogene amplified in more than 30 percent of lung, ovarian, and breast cancer cases (as high as 56 percent of lung cancers). Previously demonstrated in yeast that the retromer complex is involved in mammalian target of rapamycin (mTOR) signaling, high expression levels of mTOR have been similarly observed in GOLPH3-amplified human tumor tissues, resulting in increased pAKT activity ${ }^{[40]}$. Not only is increased pAKT associated with high metastatic potential in breast cancers, but mutations in an anchor protein such as GOLPH3 could result in endosomal retention of receptors by inhibiting their transition out of endosomes, leading to prolonged signal transduction and metastasis ${ }^{[41,42]}$. 
An event frequently observed in cancers such as breast, pancreatic, and lung is the localization of activated receptor tyrosine kinases in the perinuclear space ${ }^{[3-45]}$. While not all of these receptors have been shown to pass through the Golgi, they do appear to be subject to retrotranslocation as many of them are found in the nucleus, including fibroblast growth factor receptor (FGFR), members of the ErbB family, and TGF- $\beta$ receptor, all of which will be further discussed below ${ }^{[41,46,47]}$.

Here, we explore a range of transmembrane receptors associated with cancer and metastasis, examining their endogenous trafficking pathways, conditions in which this trafficking may be altered, and the relationship between retrotranslocation, nuclear localization, and metastasis.

\section{INSULIN RECEPTOR}

The insulin receptor (InsR) is a receptor tyrosine kinase known to traffic to the perinuclear space (rather than the TGN) and colocalize with SNARE proteins through a targeting motif in the carboxy terminus ${ }^{[48]}$. This perinuclear colocalization occurs in a subset of storage vesicles near the Golgi, driven by the high rates of intravesicular cycling associated with InsR, as only 2-5 percent of the receptor is maintained at the cell surface ${ }^{[49,50]}$. Intracellular InsR promotes the constitutive activation of AKT, resulting in glucose transporter 4 translocation, enhanced anchorage-independent growth, and altered acinar structure formation ${ }^{[50-52]}$.

\section{FGFR}

FGFR is a receptor tyrosine kinase highly involved in epithelial to mesenchymal transition (EMT) and tumorigenesis, promoting signal transduction through mitogen-activated protein kinase (MAPK) and $\beta$-catenin activity ${ }^{[53]}$. Stimulation with ligand FGF1 results in receptor retention in Rab5-positive endosomes in the perinuclear space (undetermined if in the Golgi apparatus) and promotes trafficking to the nucleus, an event modulated by importin- $\beta 1^{[46,54]}$. When bound to the ligand FGF2, FGFR is capable of inducing c-Jun and cyclin D1 mRNA expression by acting as a transcription factor at the FGF2 promoter, an event similar to that seen in EGFR ${ }^{[54-56]}$. Nuclear FGFR is highly associated with AKT-driven breast cancer metastasis to the lung and pancreatic cancer cell invasion ${ }^{[57,58]}$. Importantly, neither the FGF ligands nor FGFR contain a canonical nuclear localization sequence $(\mathrm{NLS})^{[55]}$, indicating that the nuclear localization is a result of retrotranslocation driving activated receptors from endosomes in the perinuclear space toward the nucleus.

\section{ERBB RECEPTORS}

\section{EGFR}

ErbB1, also known as HER1 or EGFR is a single pass transmembrane receptor tyrosine kinase subject to significant post-translational modifications, which affect both its activation and trafficking. Upon binding a ligand, EGFR is subject to homo/heterodimerization, transphosphorylation, and is primarily trafficked to the lysosome ${ }^{[59,60]}$. It is also capable of retrotranslocation, recycling, and other trafficking pathways, all of which are highly dependent on the localization of EGFR within the cell and additional signal transduction pathways activated in the cell ${ }^{[61-63]}$.

EGFR can bind a range of ligands, including epidermal growth factor (EGF), TGF- $\alpha$, heparin-boundEGF (HB-EGF), $\beta$-cellulin (BTC), epiregulin (EPR), and amphiregulin (AR). Upon binding a ligand, ErbB receptors dimerize and are subject to internalization and trafficking. Ligand binding triggers membrane invagination within at least $30 \mathrm{~s}$, a transient process that resets within approximately $15 \mathrm{~min}$ after exposure. All ligands promote the transport of EGFR from the plasma membrane to EEA1-positive endosomes, though AR is slightly less efficient at this ${ }^{[62,64]}$. EGF, HB-EGF, and BTC promote EGFR trafficking to the lysosome for degradation, while TGF- $\alpha$ and EPR binding primarily promote EGFR recycling ${ }^{[62]}$. EGFR-EGF binding promotes activation of multiple signaling pathways including MAPK, PI3K, phospholipase C (PLC $\gamma$ ), and AKT, leading to a host of potentially oncogenic activities when left unregulated. EGFR has been implicated 
in organ morphogenesis, maintenance and repair pathways, tumor progression, and metastasis through upregulated EGFR signaling ${ }^{[65]}$. EGFR signaling is potentiated by phosphorylation of tyrosines found in the cytoplasmic domain, whose activation is determined by ligand and dimerization partner. Phosphorylated tyrosines act as docking sites for many proteins and interactors, such as Src homology 2 or phosphotyrosine binding domain-containing proteins, including growth factor receptor-bound protein 2, Src-homology and collagen, PLC $\gamma$, PI3K subunit p85, GTPase activating protein, Cbl, and adaptor protein-2 (AP-2). EGFR phosphorylation remains active in endosomal vesicles, where EGFR is hyperphosphorylated, allowing for continued signal transduction ${ }^{[66-70]}$. Signaling through PLC has been shown to be preferentially activated when at the cell surface, while MAPK signaling continues to occur while in intracellular vesicles ${ }^{[71]}$.

PI3K signaling is also preferentially activated in endosomes, as Vieira et al. ${ }^{[66]}$ demonstrated PI3K activation is unnecessary for internalization and instead plays a role in endosomal trafficking of EGFR. Similarly, Garay et al ${ }^{[67]}$ indicated preferential AKT signaling when EGFR is internalized in clathrin-coated vesicles rather than at the plasma membrane through siRNA against clathrin.

Vesicular EGFR alternatively trafficked away from the lysosome (demonstrated with a SNX1-directed siRNA) results in augmented AKT signaling in non-small-cell lung cancer ${ }^{[72]}$, and we have previously demonstrated that endosomally retained and mislocalized EGFR is capable of upregulating AKT activity, resulting in increased metastatic potential, as well increased nuclear localization of transcription factor TAZ (transcription co-activator with a PDZ-binding domain), an event associated with cancer stem cells ${ }^{[42,73]}$. AKT is involved in driving EMT through disassembly of cell-cell junctions and upregulation of SNAIL, confirmed by loss of EMT phenotype in prostate cancer cells when treated with AKT inhibitors ${ }^{[74]}$. AKT1 kinase activity and AKT2 overexpression are associated with ovarian, breast, and thyroid cancers - three cancer types commonly hallmarked by high EGFR expression ${ }^{[75-81]}$. While AKT activation is strongly associated with the inhibition of apoptosis, at least one study has found endocytosed EGFR that does not traffic to the lysosome correlates with an induction of apoptosis ${ }^{[82]}$. More work to determine the mechanisms of these events will be required to fully understand these processes.

Though EGFR is primarily targeted to the lysosome to prevent constitutively activated signal transduction, when stimulated by EGF, it has been shown that a fraction of EGFR will be transported to the Golgi and the ER, carried via COP-I vesicles en route to trafficking to the nucleus ${ }^{[83,84]}$. Studies have shown that after 20 min of EGF stimulation, 10 percent of EGFR colocalizes to the Golgi and remains phosphorylated, even in the presence of protein synthesis inhibitors, indicating that the retrograde trafficking observed is not due to post-translational modifications ${ }^{[85]}$.

Upon translocation to the Golgi, the amino-terminal domain of EGFR sits within the lumen of the Golgi, leaving the carboxy-terminal domain exposed in the cytoplasm to interact with importin $\beta-1$ via the NLS ${ }^{[84]}$. All ErbB family members can enter the nucleus, with full-length, phosphorylated EGFR entering via the Sec61 translocon and interacting with importin $\alpha-\beta 1$ complexes $^{[43,86,87]}$. EGFR is capable of transactivational activity, but lacks a DNA-binding domain, providing a need for transcription co-factors ${ }^{[88]}$. Upon entry into the nucleus, EGFR can associate with transcription co-factors such as signal transducer and activator of transcription 3 (STAT3) to co-regulate inducible nitric oxide synthase expression and E2F1 to promote cell cycle progression, as well as the proliferation marker Ki-67 ${ }^{[88-90]}$. Nuclear EGFR interactions with proliferating cell nuclear antigen (PCNA) also promote cell cycle progression, while increasing PCNA phosphorylation and the DNA damage response ${ }^{[91,92]}$. Nuclear EGFR has been found to be associated with more than 40 percent of breast cancer tumors and 35 percent of esophageal squamous cell cancers, correlated to shorter overall survival in patients and increased metastatic potential, respectively ${ }^{[93,94]}$. Nuclear EGFR also contributes to cetuximab and gefitinib resistance, likely due to the restricted access of the therapeutics to the target protein ${ }^{[41,85]}$. Finally, the role of retrotranslocated EGFR as a transcriptional co-factor further exemplifies its kinase-independent function, highlighting the need for therapeutically targeting this process. 
We have previously demonstrated the localization of EGFR in the nucleus when interacting with the oncogenic adaptor glycoprotein mucin1 (MUC1). Notably, when in the presence of MUC1, EGFR is able to bind to chromatin and act as a co-transcriptional activator by colocalizing to the transcriptional start sites with phosphorylated RNA polymerase $\mathrm{II}^{[56]}$. EGFR has also been shown to interact with cyclin D1 in the nucleus and cyclin D1 expression is increased in EGFR-dependent mouse models and breast cancers ${ }^{[5,95-97]}$. Also seen in MUC1-expressing, EGFR-driven breast cancer mouse models were high rates of lung metastases (96 percent showing distinct pulmonary foci and the remaining 4 percent unspecified adenocarcinomas). Alternatively, in the absence of MUC1 and nuclear EGFR, no lung metastases were observed. Taken together, nuclear EGFR, particularly in the presence of MUC1, promotes EGFR transcriptional activity, increases cyclin D1 expression, and drives metastasis.

To elucidate the mechanism by which MUC1 promotes nuclear localization of EGFR, we have also demonstrated MUC1 and EGFR colocalize in EEA1-positive endosomes that are retained in the perinuclear space and actively are trafficked away from the lysosome. This allows for signal transduction to remain unattenuated, resulting in a MUC1-dependent increase in breast cancer cell migration rates, an effect completely eliminated by the introduction of a retrograde trafficking inhibitor, Retro-2. Inhibiting retrotranslocation of EGFR, even in the presence of MUC1, results in a reduced migratory phenotype through cytoskeletal rearrangement and reduction of focal adhesion kinase (FAK)-positive structures ${ }^{[41]}$.

EGFR is a pleiotropic signal transducer with a highly conserved activation and endocytosis pathway. However, during cancer, a high correlation is observed between retrograde trafficking and nuclear localization, resulting in increased metastatic events, both in vitro and in vivo.

\section{ErbB2 receptor}

ErbB2 (HER2, Neu2) is another member of the ErbB family, well-studied for its role in driving cancer through increased cell proliferation, resistance to apoptosis, and migration. A transmembrane protein found on the basolateral surface of cells, ErbB2 lacks the ability to bind ligands, therefore relying on other receptors for dimerization. While EGFR is primarily driven to the lysosome as part of its endogenous trafficking, ErbB2 is resistant to downregulation of itself or its heterodimerization partner, instead subject to rapid recycling through $\mathrm{CME}^{[98]}$.

ErbB2 activation is dependent upon heterodimerization with another ErbB receptor, as it lacks a ligandbinding domain to allow for self-activation. It can also become active through extensive overexpression, which promotes the formation of ErbB2 heterodimers responsible for enhancing the signal transduction associated with their dimer partner, an event seen in colon, gastric, prostate, and breast cancers ${ }^{[59,61,99]}$. ErbB2 overexpression in breast cancer is so well-characterized that it is responsible for an entire classification: HER2+; studies have shown it is amplified in more than 20 percent of breast cancer tumors, making it a strong predictor of survival and time to relapse ${ }^{[100,101]}$.

Upregulation of ErbB2 is known to promote lymph node metastasis, as well as significantly increase metastasis rates to the brain, liver, and lung ${ }^{[102]}$. Like all members of the ErbB family, ErbB2 can enter the nucleus, where it can interact with promoters, including matrix metalloproteinase 16, p53-related protein kinase, and cyclooxygenase-2 (COX-2). The COX-2 gene is known to drive metastasis in cancer cells and coexpression of these two proteins has been reported in colon, cholangiocarcinoma, and breast cancers ${ }^{[103]}$. Exploring further, Edwards et al. ${ }^{[104]}$ reported that prostate tumors with increased HER2 copy number also had increased levels of COX-2 expression while Thorat et al. ${ }^{[105]}$ and Glynn et al. ${ }^{[106]}$ demonstrated that COX-2 levels are highest (if not statistically significant) in HER2+ breast cancer ( $v s$. luminal A/B and triple negative breast cancers) and that positive COX-2 expression in HER2+ patients is directly correlated to increased phosphorylation of AKT and poor survival outcomes ${ }^{[104-106]}$. 
ErbB2 overexpression is seen in a variety of cancers and is strongly associated with metastatic events and inhibited degradation of activated receptors. Lacking intrinsic ability to self-phosphorylate, ErbB2 receptors bind with other members of the ErbB family to induce activation and potentiate signal transduction, frequently resulting in increased COX-2 and AKT activity due to nuclear localization, events commonly seen in metastasis.

\section{ErbB3 receptor}

ErbB3 is a catalytically inhibited member of the ErbB family, bearing a mutated tyrosine kinase domain and relying on heterodimerization partners for phosphorylation. As such, ErbB3 frequently presents with decreased levels of ubiquitination in comparison to EGFR, emphasizing the inefficiency of ErbB3 to be targeted to the lysosome ${ }^{[107]}$. Heterodimers between ErbB2 and ErbB3 lead to strong activation of the MAPK and PI3K/AKT pathways, promoting survival and proliferation by ErbB2 and ErbB3, respectively ${ }^{[108-110]}$. Through these signaling pathways ErbB3 activity is associated with loss of cellular differentiation and increased expression of MUC1 in carcinomas, as well as driving proliferation in ErbB2-positive breast cancer cells lines ${ }^{[108,111]}$. ErbB3 is subject to significantly slower rates of endocytosis than EGF-bound EGFR due to the anti-internalization regions within the C-terminus, allowing for longer periods of receptor activation (when in a heterodimer) ${ }^{[71,12]}$. This delayed trafficking results in perinuclear accumulation, thereby allowing nuclear localization via retrotranslocation ${ }^{[13]}$. Once in the nucleus, ErbB3 presents in an activated, uncleaved format, capable of associating with the Cyclin D1 promoter to drive cell proliferation, similar to the mechanism seen in $\mathrm{EGFR}^{[54,56,114]}$. Clinical data has shown in prostate cancer, nuclear localization of ErbB3 present in 100 percent of hormone-refractory samples and 40 percent of hormone-sensitive samples, in contrast to the negligible amount seen in normal prostate tissue, directly associated with disease progression risks $^{[115]}$. Nuclear ErbB3 also presents at higher frequency in prostate cancer metastases (particularly bone) than in primary tumor sites ${ }^{[116]}$, indicating that retrotranslocated ErbB3 is likely involved in the metastasis of prostate cancers.

\section{ErbB4 receptor}

The fourth and final member of the ErbB family, ErbB4 maintains homology to ErbB1- capable of binding ligands (EPR, HB-EGF, BTC, and neuregulins 1-4) and a tyrosine kinase domain capable of catalytic activation ${ }^{[112,117]}$. Once bound to a ligand, ErbB4 promotes signal transduction through a host of pathways, including PLCy, PI3K, and STAT ${ }^{[118]}$.

Post-activation, ErbB4 is subject to dual-protease cleavage in both the extracellular domain and the transmembrane domain, resulting in an active, cleaved cytoplasmic domain capable of nuclear translocation (upon binding to neuregulin). ErbB4 activity is highly associated with poor prognosis and increased metastasis in Ewing sarcoma, activating PI3K-AKT and altering FAKs to drive invasion ${ }^{[119]}$. Expression of ErbB4 also increases in colorectal cancer as disease stage progresses, indicating a potential role in driving cancer progression, though its expression is associated with improved prognosis in estrogen-receptor positive breast cancers ${ }^{[120,121]}$. Highly enriched in neuronal plaques of patients with Alzheimer disease, nuclear localization can lead to transcriptional activation of genes that regulate neurodegeneration ${ }^{[118]}$. To achieve nuclear localization, it is possible that active, cleaved ErbB4 reaches the Sec61 translocon in the ER and is processed while avoiding ERAD-ubiquitin-associated proteolysis, in a mechanism similar to EGFR nuclear translocation $^{[86,118]}$.

In addition to the tyrosine kinase receptors described above, at least two non-tyrosine kinase receptors, ILR2 and TGF- $\beta$ receptor, also undergo retrotranslocation in cancer.

\section{ILR2}

Found in fibroblasts, epithelial, and neuronal cells, ILR2, upon ligand binding is internalized and targeted for degradation through acidification, similar to EGFR and the transferrin receptor ${ }^{[59,122,123]}$. ILR2 has also 
demonstrated an ability to undergo endocytosis in the absence of clathrin or AP-2 at relatively uninhibited rates, likely due to the nature of the receptor to promote T-cell proliferation - a system that would benefit from redundancies ${ }^{[122]}$.

When undergoing non-CME, ILR2 is internalized through detergent-resistant membrane domains, similar to the mechanism employed by cholera toxin ${ }^{[124,125]}$. Upon entry into the cell, vesicles containing ILR2 are found in the glycolipid rich areas of the cell, particularly in the perinuclear spaces and near the organelle responsible for glycolipid modification, the Golgi ${ }^{[124]}$. Retention of the receptor in the perinuclear space is common in cancer, as ILR2 expression can be a predictor of patient survival and is significantly reduced at cell surface levels in advanced ovarian cancers ${ }^{[126,127]}$.

\section{TGF- $\beta$ RECEPTOR}

TGF- $\beta$ is a secreted ligand involved in modulating cellular growth and arrest, differentiation, and immune responses, capable of binding to type I or type II single-pass transmembrane receptors ${ }^{[47,128-130]}$. Unlike other receptors presented in this review, TGF- $\beta$ receptor can be internalized with or without ligand binding, resulting in either CME-assisted recycling or non-CME degradation ${ }^{[47]}$.

When subject to CME, TGF- $\beta$ receptor is sorted into EEA1-positive vesicles where it acts to activate SMAD2 and potentiate TGF- $\beta$ signal transduction. Activated receptors localize to the perinuclear space and remain in endosomes, a phenotype also seen with the transferrin receptor and which we have previously shown to occur with EGFR in breast cancer ${ }^{[41,47]}$. Alternatively, TGF- $\beta$ receptor can also be sorted via lipid rafts to interact with SMAD7. In either scenario, SMAD signaling nuclear translocation require internalization of TGF- $\beta$ receptor ${ }^{[131,132]}$.

Taken together, a range of transmembrane proteins are subject to retrotranslocation. While some localize to the perinuclear space and can be internalized into the nucleus, such as InsR, FGFR, TGF- $\beta$ receptor, and ILR2, others can enter the Golgi, such as ErbB family members, and remain active and promote metastasis. ErbB receptors also localize to the nucleus, resulting in transcriptional activity of cancer genes and pathways.

\section{THERAPEUTIC TARGETING OF RETROTRANSLOCATION}

Given the metastatic and oncogenic activity associated with nuclear localization of activated receptor tyrosine kinases driven by retrograde trafficking, it is important to explore potential mechanisms by which retrotranslocation could be inhibited as a therapeutic target.

It has been demonstrated that introduction of retrograde inhibitors can drastically reduce the cytotoxic effects of toxins like ricin, cholera, or shiga, which rely on retrograde trafficking to be distributed throughout cells. A compound designated Retro-2 works to inhibit toxin trafficking from the early endosome to the trans-Golgi interface, actively protecting cells from ricin toxicity 2-3 fold in vitro and almost 50 percent of mice from airborne exposure to the ricin toxin (in comparison to the 11 percent that survived in the absence of retrograde inhibition $)^{[133]}$. Retro-2 does not inhibit plasma membrane budding or endosome formation; rather it inhibits transport of endosomes to the TGN without affecting Golgi morphology (or that of EEA1 or Rab11). Endocytic degradation and recycling pathways also remain unaltered. However, SNARE proteins syntaxin 5 and 6 were subject to alterations in localization, indicating Retro-2 may work to inhibit retromer trafficking of endosomes or inhibit interactions of endosomes with the Golgi ${ }^{[133]}$.

We have previously demonstrated the importance of retrograde trafficking in promoting a migratory phenotype in association with the presence of $\mathrm{MUC1}^{[41]}$. Treatment of breast cancer cells in vitro with the retrograde trafficking inhibitor Retro-2 led to the inhibition of MUC1-driven migration and re-introduction 
of EGFR trafficking to the lysosome for degradation. Given this, a potential therapeutic option may be to inhibit retrograde trafficking of EGFR, possibly through the use of Retro-2, though no studies have yet examined the effects in humans.

Alternative to inhibiting retrograde trafficking, current research has demonstrated an effort to capture the retrotranslocation mechanisms of toxins and repurpose them for drug delivery. Using the non-toxic subunit B of Shiga-like toxin, various attempts at conjugating therapeutics, incorporating nanoparticles, or developing fusion proteins have been attempted (reviewed in Luginbuehl et al. ${ }^{[134]}$ ).

Should inhibition of retrograde trafficking prove untenable in patients, a secondary approach to inhibition of the oncogenic activity driven by nuclear receptor tyrosine kinases would target receptors within the nucleus. Nuclear EGFR has been shown to associate with promoter regions of a variety of proteins, including cyclin D1, activated STAT3, E2F1, DNA-dependent protein kinase, and other nuclear targets, while nuclear ErbB2 is capable of interacting with COX-2, all resulting in increases in tumorigenesis, proliferation, metastasis, chemoresistance, and radioresistance ${ }^{[106,135]}$. ErbB2-EEA1 complexes are capable of nuclear transport, and given the high affinity of EGFR-MUC1 complexes in EEA1 positive vesicles in the perinuclear space of cells after extended exposure to EGF ligand, it is feasible that EGFR endosomal machinery is promoting nuclear localization of EGFR in a similar mechanism ${ }^{[41,87,136]}$.

Radiation treatment of cells is known to drive EGFR to the nucleus as part of the DNA-repair pathway mechanism, and studies have shown that treatment of irradiated cells with cetuximab will inhibit EGFR trafficking to the nucleus in both lung carcinoma and breast cancer cell lines ${ }^{[137]}$. Radiation treatment, along with neuregulin stimulation or trastuzumab will also promote retrograde trafficking of ErbB2-ErbB3 dimers to the nucleus, visible by super-resolution confocal microscopy as demonstrated by Pilarczyk et al. ${ }^{[138]}$. Nuclear import might also be inhibited by targeting the importin- $\beta 1$ molecule through treatment with small molecule inhibitors such as Karyostatin1 A to disrupt importin interactions with the GTPase Ran ${ }^{[139]}$.

Treatment of cells with 1,25-dihydroxyvitamin D was found to prevent EGFR from entering the nucleus by promoting intracellular localization of inactive, unphosphorylated EGFR, even if bound to a ligand, to early endosomes. By doing so, $1,25(\mathrm{OH})_{2} \mathrm{D}_{3}$ downregulated the oncogenic activity associated with nuclear EGFR without targeting vesicles to the lysosome ${ }^{[140]}$. This treatment could feasibly be used to target two processes associated with cancer progression - inhibit nuclear targeting of EGFR and convert endosomally localized EGFR to an inert state, essentially nullifying the need for lysosomal degradation.

\section{CONCLUSION}

Retrograde trafficking of transmembrane proteins, with an emphasis on receptor tyrosine kinases, results in alternatively trafficked activated receptors accumulating in the perinuclear space of cells. The primary effect of these undegraded, endosomally-retained, actively signaling receptors is the unabrogated transduction of the PI3K/AKT pathway - resulting in upregulation of cancer metastasis. Not only that, but for those receptors that transit through the Golgi or come in sufficient proximity to a nuclear pore, active receptors can now act as transcriptional activators to a host of oncogenic activities. Seen in cancers ranging from Ewing sarcoma to breast to prostate and more, it is clear this ubiquitous mechanism of translocation is responsible for trafficking receptors to the wrong place at the wrong time, driving cancer metastasis. Future therapeutics may choose to inhibit retrograde trafficking to prevent mislocalization or focus instead on targeting receptors after their localization has already been altered. Given current treatment plans for many cancers now involve adjuvant therapies, the most efficient method for overcoming metastasis-promoting retrograde trafficking may involve some combination of both. 


\section{DECLARATIONS}

\section{Acknowledgments}

We would like to thank Dr. Kel-Eton S and Dr. Odoonce Y for their insightful discussion and commentary.

\section{Authors' contributions}

Written and edited manuscript: Maisel SA, Schroeder J

\section{Availability of data and materials}

Not applicable.

\section{Financial support and sponsorship}

None.

\section{Conflicts of interest}

Both authors declared that there are no conflicts of interest.

\section{Ethical approval and consent to participate}

Not applicable.

\section{Consent for publication}

Not applicable.

\section{Copyright}

(c) The Author(s) 2019.

\section{REFERENCES}

1. Zhang P, Monteiro da Silva G, Deatherage C, Burd C, DiMaio D. Cell-penetrating peptide mediates intracellular membrane passage of human papillomavirus L2 protein to trigger retrograde trafficking. Cell 2018;174:1465-76.

2. Klinger SC, Siupka P, Nielsen MS. Retromer-mediated trafficking of transmembrane receptors and transporters. Membranes (Basel) 2015;5:288-306.

3. Johannes L, Popoff V. Tracing the retrograde route in protein trafficking. Cell 2008;135:1175-87.

4. Bonifacino JS, Rojas R. Retrograde transport from endosomes to the trans-Golgi network. Nat Rev Mol Cell Biol 2006;7:568-79.

5. Lemmon MA, Schlessinger J. Cell signaling by receptor tyrosine kinases. Cell 2010;141:1117-34.

6. Selyunin AS, Iles LR, Bartholomeusz G, Mukhopadhyay S. Genome-wide siRNA screen identifies UNC50 as a regulator of Shiga toxin 2 trafficking. J Cell Biol 2017;216:3249-62.

7. Matsudaira T, Niki T, Taguchi T, Arai H. Transport of the cholera toxin B-subunit from recycling endosomes to the Golgi requires clathrin and AP-1. J Cell Sci 2015;128:3131-42.

8. Taubenschmid J, Stadlmann J, Jost M, Klokk TI, Rillahan CD, et al. A vital sugar code for ricin toxicity. Cell Res 2017;27:1351-64.

9. Seaman MN. The retromer complex - endosomal protein recycling and beyond. J Cell Sci 2012;125:4693-702.

10. Chia PZ, Gasnereau I, Lieu ZZ, Gleeson PA. Rab9-dependent retrograde transport and endosomal sorting of the endopeptidase furin. J Cell Sci 2011;124:2401-13.

11. Zhang X, Song W. The role of APP and BACE1 trafficking in APP processing and amyloid-beta generation. Alzheimers Res Ther 2013;5:46.

12. Makaraci P, Kim K. Trans-Golgi network-bound cargo traffic. Eur J Cell Biol 2018;97:137-49.

13. McKenzie JE, Raisley B, Zhou X, Naslavsky N, Taguchi T, et al. Retromer guides STxB and CD8-M6PR from early to recycling endosomes, EHD1 guides STxB from recycling endosome to Golgi. Traffic 2012;13:1140-59.

14. Purushothaman LK, Arlt H, Kuhlee A, Raunser S, Ungermann C. Retromer-driven membrane tubulation separates endosomal recycling from Rab7/Ypt7-dependent fusion. Mol Biol Cell 2017;28:783-91.

15. Zaremba S, Keen JH. Assembly polypeptides from coated vesicles mediate reassembly of unique clathrin coats. J Cell Biol 1983;97:1339-47.

16. Mellman I, Yarden Y. Endocytosis and cancer. Cold Spring Harb Perspect Biol 2013;5:a016949.

17. Lauvrak SU, Torgersen ML, Sandvig K. Efficient endosome-to-Golgi transport of Shiga toxin is dependent on dynamin and clathrin. J Cell Sci 2004;117:2321-31.

18. Scott CC, Vacca F, Gruenberg J. Endosome maturation, transport and functions. Semin Cell Dev Biol 2014;31:2-10.

19. Worby CA, Dixon JE. Sorting out the cellular functions of sorting nexins. Nat Rev Mol Cell Biol 2002;3:919-31. 
20. De Camilli P, Emr SD, McPherson PS, Novick P. Phosphoinositides as regulators in membrane traffic. Science 1996;271:1533-9.

21. Kurten RC, Cadena DL, Gill GN. Enhanced degradation of EGF receptors by a sorting nexin, SNX1. Science 1996;272:1008-10.

22. Duclos CM, Champagne A, Carrier JC, Saucier C, Lavoie CL, et al. Caspases play in traffic. Cell Death Dis 2017;8:e2636.

23. Chin LS, Raynor MC, Wei X, Chen HQ, Li L, et al. Hrs interacts with sorting nexin 1 and regulates degradation of epidermal growth factor receptor. J Biol Chem 2001;276:7069-78.

24. Yang XZ, Li XX, Zhang YJ, Rodriguez-Rodriguez L, Xiang MQ, et al. Rab1 in cell signaling, cancer and other diseases. Oncogene 2016;35:5699-704

25. Chia WJ, Tang BL. Emerging roles for Rab family GTPases in human cancer. Biochim Biophys Acta 2009;1795:110-6.

26. Stenmark H. Rab GTPases as coordinators of vesicle traffic. Nat Rev Mol Cell Biol 2009;10:513-25.

27. Cheng KW, Lahad JP, Gray JW, Mills GB. Emerging role of RAB GTPases in cancer and human disease. Cancer Res 2005;65:2516-9.

28. Short B, Preisinger C, Schaletzky J, Kopajtich R, Barr FA. The Rab6 GTPase regulates recruitment of the dynactin complex to Golgi membrane. Curr Biol 2002;12:1792-5.

29. Ceresa BP. Regulation of EGFR endocytic trafficking by rab proteins. Histol Histopathol 2006;21:987-93.

30. Zhou Y, Wu B, Li JH, Nan G, Jiang JL, et al. Rab22a enhances CD147 recycling and is required for lung cancer cell migration and invasion. Exp Cell Res 2017;357:9-16.

31. Xiong F, Liu K, Zhang F, Sha K1 Wang X. et al. MiR-204 inhibits the proliferation and invasion of renal cell carcinoma by inhibiting RAB22A expression. Oncol Rep 2016;35:3000-8.

32. Wang T, Gilkes DM, Takano N, Xiang L, Luo W, et al. Hypoxia-inducible factors and RAB22A mediate formation of microvesicles that stimulate breast cancer invasion and metastasis. Proc Natl Acad Sci U S A 2014;111:E3234-42.

33. Zhang Y, Zhao FJ, Chen LL, Wang LQ, Nephew KP, et al. MiR-373 targeting of the Rab22a oncogene suppresses tumor invasion and metastasis in ovarian cancer. Oncotarget 2014;5:12291-303.

34. Yang D, Liu G, Wang K. miR-203 acts as a tumor suppressor gene in osteosarcoma by regulating RAB22A. PLoS One 2015;10:e0132225.

35. Mallard F, Tang BL, Galli T, Tenza D, Saint-Pol A, et al. Early/recycling endosomes-to-TGN transport involves two SNARE complexes and a Rab6 isoform. J Cell Biol 2002;156:653-64.

36. Galvez T, Gilleron J, Zerial M, O’Sullivan GA. SnapShot: mammalian rab proteins in endocytic trafficking. Cell 2012;151:234-e2.

37. White J, Johannes L, Mallard F, Girod A, Grill S, et al. Rab6 coordinates a novel Golgi to ER retrograde transport pathway in live cells. J Cell Biol 1999;147:743-60.

38. Personnic N, Bärlocher K, Finsel I, Hilbi H. Subversion of retrograde trafficking by translocated pathogen effectors. Trends Microbiol 2016;24:450-62.

39. Sotiriou C, Neo SY, McShane LM, Korn EL, Long PM, et al. Breast cancer classification and prognosis based on gene expression profiles from a population-based study. Proc Natl Acad Sci U S A 2003;100:10393-8.

40. Scott KL, Kabbarah O, Liang MC, Ivanova E, Anagnostou V, et al. GOLPH3 modulates mTOR signalling and rapamycin sensitivity in cancer. Nature 2009;459:1085-90.

41. Maisel S, Broka D, Schroeder J. Intravesicular epidermal growth factor receptor subject to retrograde trafficking drives epidermal growth factor-dependent migration. Oncotarget 2017;9:6463-77.

42. Greenwood E, Maisel S, Ebertz D, Russ A, Pandey R, et al. Llgl1 prevents metaplastic survival driven by epidermal growth factor dependent migration. Oncotarget 2016;7:60776-92.

43. Merlin J, Stechly L, de Beaucé S, Monté D, Leteurtre E, et al. Galectin-3 regulates MUC1 and EGFR cellular distribution and EGFR downstream pathways in pancreatic cancer cells. Oncogene 2011;30:2514-25.

44. Khan EM, Heidinger JM, Levy M, Lisanti MP, Ravid T, et al. Epidermal growth factor receptor exposed to oxidative stress undergoes Srcand caveolin-1-dependent perinuclear trafficking. J Biol Chem 2006;281:14486-93.

45. Chung BM, Raja SM, Clubb RJ, Tu C, George M, et al. Aberrant trafficking of NSCLC-associated EGFR mutants through the endocytic recycling pathway promotes interaction with Src. BMC Cell Biol 2009;10:84.

46. Maher PA. Nuclear translocation of fibroblast growth factor (FGF) receptors in response to FGF-2. J Cell Biol 1996;134:529-36.

47. Mitchell H, Choudhury A, Pagano RE, Leof EB. Ligand-dependent and -independent transforming growth factor-beta receptor recycling regulated by clathrin-mediated endocytosis and Rab11. Mol Biol Cell 2004;15:4166-78.

48. Shewan AM, van Dam EM, Martin S, Luen TB, Hong W, et al. GLUT4 recycles via a trans-Golgi network (TGN) subdomain enriched in syntaxins 6 and 16 but not TGN38: involvement of an acidic targeting motif. Mol Biol Cell 2003;14:973-86.

49. Ralston E, Ploug T. GLUT4 in cultured skeletal myotubes is segregated from the transferrin receptor and stored in vesicles associated with TGN. J Cell Sci 1996;109:2967-78.

50. Kanzaki M. Insulin receptor signals regulating GLUT4 translocation and actin dynamics. Endocr J 2006;53:267-93.

51. Zhang H, Fagan DH, Zeng X, Freeman KT, Sachdev D, et al. Inhibition of cancer cell proliferation and metastasis by insulin receptor downregulation. Oncogene 2010;29:2517-27.

52. Dearth RK, Cui X, Kim HJ, Kuiatse I, Lawrence NA, et al. Mammary tumorigenesis and metastasis caused by overexpression of insulin receptor substrate 1 (IRS-1) or IRS-2. Mol Cell Biol 2006;26:9302-14.

53. Bryant DM, Wylie FG, Stow JL. Regulation of endocytosis, nuclear translocation, and signaling of fibroblast growth factor receptor 1 by E-cadherin. Mol Biol Cell 2005;16:14-23.

54. Carpenter G. Nuclear localization and possible functions of receptor tyrosine kinases. Curr Opin Cell Biol 2003;15:143-8.

55. Reilly JF, Maher PA. Importin beta-mediated nuclear import of fibroblast growth factor receptor: role in cell proliferation. J Cell Biol 2001;152:1307-12.

56. Bitler BG, Goverdhan A, Schroeder JA. MUC1 regulates nuclear localization and function of the epidermal growth factor receptor. J Cell Sci 2010;123:1716-23.

57. Ye T, Wei X, Yin T, Xia Y, Li D, et al. Inhibition of FGFR signaling by PD173074 improves antitumor immunity and impairs breast cancer 
metastasis. Breast Cancer Res Treat 2014;143:435-46.

58. Coleman SJ, Chioni AM, Ghallab M, Anderson RK, Lemoine NR, et al. Nuclear translocation of FGFR1 and FGF2 in pancreatic stellate cells facilitates pancreatic cancer cell invasion. EMBO Mol Med 2014;6:467-81.

59. Yarden Y, Sliwkowski MX. Untangling the ErbB signaling network. Nat Rev Mol Cell Biol 2001;2:127-37.

60. Hopkins CR, Miller K, Beardmore JM. Receptor-mediated endocytosis of transferrin and epidermal growth factor receptors: a comparison of constitutive and ligand-induced uptake. J Cell Sci Supp 1985;3:173-86.

61. Sorkin A, Goh LK. Endocytosis and intracellular trafficking of ErbBs. Exp Cell Res 2008;314:3093-106.

62. Roepstorff K, Grandal MV, Henriksen L, Knudsen SL, Lerdrup M, et al. Differential effects of EGFR ligands on endocytic sorting of the receptor. Traffic 2009; 10:1115-27.

63. Willmarth NE, Baillo A, Dziubinski ML, Wilson K, Riese DJ 2nd, et al. Altered EGFR localization and degradation in human breast cancer cells with an amphiregulin/EGFR autocrine loop. Cell Signal 2009;21:212-9.

64. Haigler HT, McKanna JA, Cohen S. Rapid stimulation of pinocytosis in human carcinoma cells A-431 by epidermal growth factor. J Cell Biol 1979;83:82-90

65. Hanawa M, Suzuki S, Dobashi Y, Yamane T, Kono K, et al. EGFR protein overexpression and gene amplification in squamous cell carcinomas of the esophagus. Int J Cancer 2006;118:1173-80.

66. Vieira AV, Lamaze C, Schmid SL. Control of EGF receptor signaling by clathrin-mediated endocytosis. Science 1996;274:2086-9.

67. Garay C, Judge G, Lucarelli S, Bautista S, Pandey R, et al. Epidermal growth factor-stimulated Akt phosphorylation requires clathrin or ErbB2 but not receptor endocytosis. Mol Biol Cell 2015;26:3504-19.

68. Wang Y, Pennock S, Chen X, Wang Z. Endosomal signaling of epidermal growth factor receptor stimulates signal transduction pathways leading to cell survival. Mol Cell Biol 2002;22:7279-90.

69. Jorissen RN, Walker F, Pouliot N, Garrett TP, Ward CW, et al. Epidermal growth factor receptor: mechanisms of activation and signalling. Exp Cell Res 2003;284:31-53

70. Sebastian S, Settleman J, Reshkin SJ, Azzariti A, Bellizzi A, et al. The complexity of targeting EGFR signalling in cancer: from expression to turnover. Biochim Biophys Acta 2006;1766:120-39.

71. Wiley HS. Trafficking of the ErbB receptors and its influence on signaling. Exp Cell Res 2003;284:78-88

72. Nishimura Y, Takiguchi S, Ito S, Itoh K. EGF-stimulated AKT activation is mediated by EGFR recycling via an early endocytic pathway in a gefitinibresistant human lung cancer cell line. Int J Oncol 2015;46:1721-9.

73. Cordenonsi M, Zanconato F, Azzolin L, Forcato M, Rosato A, et al. The Hippo transducer TAZ confers cancer stem cell-related traits on breast cancer cells. Cell 2011;147:759-72.

74. Gan Y, Shi C, Inge L, Hibner M, Balducci J, et al. Differential roles of ERK and Akt pathways in regulation of EGFR-mediated signaling and motility in prostate cancer cells. Oncogene 2010;29:4947-58.

75. Bellacosa A, de Feo D, Godwin AK, Bell DW, Cheng JQ, et al. Molecular alterations of the AKT2 oncogene in ovarian and breast carcinomas. Int J Cancer 1995;64:280-5

76. Sun M, Wang G, Paciga JE, Feldman RI, Yuan ZQ, et al. AKT1/PKB $\alpha$ kinase is frequently elevated in human cancers and its constitutive activation is required for oncogenic transformation in NIH3T3 cells. Am J Pathol 2001;159:431-7.

77. Ringel MD, Hayre N, Saito J, Saunier B, Schuppert F, et al. Overexpression and overactivation of Akt in thyroid carcinoma. Cancer Res 2001;61:6105-11.

78. Sheng Q, Liu J. The therapeutic potential of targeting the EGFR family in epithelial ovarian cancer. Br J Cancer 2011;104:1241-5.

79. Meng Q, Xia C, Fang J, Rojanasakul Y, Jiang BH. Role of PI3K and AKT specific isoforms in ovarian cancer cell migration, invasion and proliferation through the p70S6K1 pathway. Cell Signal 2006;18:2262-71.

80. Sainsbury JR, Farndon JR, Needham GK, Malcolm AJ, Harris AL. Epidermal-growth-factor receptor status as predictor of early recurrence of and death from breast cancer. Lancet 1987;1:1398-402.

81. Schiff BA, McMurphy AB, Jasser SA, Younes MN, Doan D, et al. Epidermal growth factor receptor (EGFR) is overexpressed in anaplastic thyroid cancer, and the EGFR inhibitor gefitinib inhibits the growth of anaplastic thyroid cancer. Clin Cancer Res 2004;10:8594-602.

82. Hyatt DC, Ceresa BP. Cellular localization of the activated EGFR determines its effect on cell growth in MDA-MB-468 cells. Exp Cell Res 2008;314:3415-25.

83. Wang YN, Lee HH, Lee HJ, Du Y, Yamaguchi H, et al. Membrane-bound trafficking regulates nuclear transport of integral epidermal growth factor receptor (EGFR) and ErbB-2. J Biol Chem 2012;287:16869-79.

84. Wang YN, Wang H, Yamaguchi H, Lee HJ, Lee HH, et al. COPI-mediated retrograde trafficking from the Golgi to the ER regulates EGFR nuclear transport. Biochem Biophys Res Commun 2010;399:498-504.

85. Du Y, Shen J, Hsu JL, Han Z, Hsu MC, et al. Syntaxin 6-mediated Golgi translocation plays an important role in nuclear functions of EGFR through microtubule-dependent trafficking. Oncogene 2014;33:756-70.

86. Liao HJ, Carpenter G. Role of the Sec61 translocon in EGF receptor trafficking to the nucleus and gene expression. Mol Biol Cell 2007;18:1064-72.

87. Lo HW, Ali-Seyed M, Wu Y, Bartholomeusz G, Hsu SC, et al. Nuclear-cytoplasmic transport of EGFR involves receptor endocytosis, importin beta1 and CRM1. J Cell Biochem 2006;98:1570-83

88. Hanada N, Lo HW, Day CP, Pan Y, Nakajima Y, et al. Co-regulation of B-Myb expression by E2F1 and EGF receptor. Mol Carcinog 2006;45:10-7.

89. Lo HW, Hsu SC, Ali-Seyed M, Gunduz M, Xia W, et al. Nuclear interaction of EGFR and STAT3 in the activation of the iNOS/NO pathway. Cancer Cell 2005; 7:575-89.

90. Lo HW, Xia W, Wei Y, Ali-Seyed M, Huang SF, et al. Novel prognostic value of nuclear epidermal growth factor receptor in breast cancer. Cancer Res 2005;65:338-48.

91. Ortega J, Li JY, Lee S, Tong D, Gu L, et al. Phosphorylation of PCNA by EGFR inhibits mismatch repair and promotes misincorporation during DNA synthesis. Proc Natl Acad Sci U S A 2015;112:5667-72.

92. Saloura V, Vougiouklakis T, Zewde M, Deng X, Kiyotani K, et al. WHSC1L1-mediated EGFR mono-methylation enhances the cytoplasmic 
and nuclear oncogenic activity of EGFR in head and neck cancer. Sci Rep 2017;7:40664.

93. Hadzisejdić I, Mustać E, Jonjić N, Petković M, Grahovac B. Nuclear EGFR in ductal invasive breast cancer: correlation with cyclin-D1 and prognosis. Mod Pathol 2010;23:392-403.

94. Hoshino M, Fukui H, Ono Y, Sekikawa A, Ichikawa K, et al. Nuclear expression of phosphorylated EGFR is associated with poor prognosis of patients with esophageal squamous cell carcinoma. Pathobiology 2007;74:15-21.

95. Lin SY, Makino K, Xia W, Matin A, Wen Y, et al. Nuclear localization of EGF receptor and its potential new role as a transcription factor. Nat Cell Biol 2001;3:802-8.

96. Pochampalli MR, Bitler BG, Schroeder JA. Transforming growth factor alpha dependent cancer progression is modulated by Muc1. Cancer Res 2007;67:6591-8.

97. Aggarwal P, Lessie MD, Lin DI, Pontano L, Gladden AB, et al. Nuclear accumulation of cyclin D1 during S phase inhibits Cul4-dependent Cdt1 proteolysis and triggers p53-dependent DNA rereplication. Genes Dev 2007;21:2908-22.

98. Bertelsen V, Stang E. The mysterious ways of ErbB2/HER2 trafficking. Membranes (Basel) 2014;4:424-46.

99. Normanno N, De Luca A, Bianco C, Strizzi L, Mancino M, et al. Epidermal growth factor receptor (EGFR) signaling in cancer. Gene 2006;366:2-16.

100. Slamon DJ, Clark GM, Wong SG, Levin WJ, Ullrich A, et al. Human breast cancer: correlation of relapse and survival with amplification of the HER-2/neu oncogene. Science 1987;235:177-82.

101. Slamon DJ, Godolphin W, Jones LA, Holt JA, Wong SG, et al. Studies of the HER-2/neu proto-oncogene in human breast and ovarian cancer. Science 1989;244:707-12.

102. Kennecke H, Yerushalmi R, Woods R, Cheang MC, Voduc D, et al. Metastatic behavior of breast cancer subtypes. J Clin Oncol 2010;28:3271-7.

103. Wang SC, Lien HC, Xia W, Chen IF, Lo HW, et al. Binding at and transactivation of the COX-2 promoter by nuclear tyrosine kinase receptor ErbB-2. Cancer Cell 2004;6:251-61.

104. Edwards J, Mukherjee R, Munro AF, Wells AC, Almushatat A, et al. HER2 and COX2 expression in human prostate cancer. Eur J Cancer 2004; $40: 50-5$

105. Thorat D, Sahu A, Behera R, Lohite K, Deshmukh S, et al. Association of osteopontin and cyclooxygenase-2 expression with breast cancer subtypes and their use as potential biomarkers. Oncol Lett 2013;6:1559-64.

106. Glynn SA, Prueitt RL, Ridnour LA, Boersma BJ, Dorsey TM, et al. COX-2 activation is associated with Akt phosphorylation and poor survival in ER-negative, HER2-positive breast cancer. BMC Cancer 2010;10:626.

107. Waterman H, Alroy I, Strano S, Seger R, Yarden Y. The C-terminus of the kinase-defective neuregulin receptor ErbB-3 confers mitogenic superiority and dictates endocytic routing. EMBO J 1999;18:3348-58.

108. Holbro T, Beerli RR, Maurer F, Koziczak M, Barbas CF 3rd, et al. The ErbB2/ErbB3 heterodimer functions as an oncogenic unit: ErbB2 requires ErbB3 to drive breast tumor cell proliferation. Proc Natl Acad Sci U S A 2003;100:8933-8.

109. Alimandi M, Romano A, Curia MC, Muraro R, Fedi P, et al. Cooperative signaling of ErbB3 and ErbB2 in neoplastic transformation and human mammary carcinomas. Oncogene 1995;10:1813-21.

110. Wallasch C, Weiss FU, Niederfellner G, Jallal B, Issing W, et al. Heregulin-dependent regulation of HER2/neu oncogenic signaling by heterodimerization with HER3. EMBO J 1995;14:4267-75.

111. Kobayashi M, Iwamatsu A, Shinohara-Kanda A, Ihara S, Fukui Y. Activation of ErbB3-PI3-kinase pathway is correlated with malignant phenotypes of adenocarcinomas. Oncogene 2003;22:1294-301.

112. Roepstorff K, Grøvdal L, Grandal M, Lerdrup M, van Deurs B. Endocytic downregulation of ErbB receptors: mechanisms and relevance in cancer. Histochem Cell Biol 2008;129:563-78.

113. Frazier NM, Brand T, Gordan JD, Grandis J, Jura N. Overexpression-mediated activation of MET in the Golgi promotes HER3/ERBB3 phosphorylation. Oncogene 2018; doi: 10.1038/s41388-018-0537-0.

114. Andrique L, Fauvin D, El Maassarani M, Colasson H, Vannier B, et al. ErbB3(80 kDa), a nuclear variant of the ErbB3 receptor, binds to the cyclin D1 promoter to activate cell proliferation but is negatively controlled by p14ARF. Cell Signal 2012;24:1074-85.

115. Koumakpayi IH, Diallo JS, Le Page C, Lessard L, Gleave M, et al. Expression and nuclear localization of ErbB3 in prostate cancer. Clin Cancer Res 2006;12:2730-7.

116. Cheng CJ, Ye XC, Vakar-Lopez F, Kim J, Tu SM, et al. Bone microenvironment and androgen status modulate subcellular localization of ErbB3 in prostate cancer cells. Mol Cancer Res 2007;5:675-84.

117. Yarden Y, Pines G. The ERBB network: at last, cancer therapy meets systems biology. Nat Rev Cancer 2012;12:553-63.

118. Schlessinger J, Lemmon MA. Nuclear signaling by receptor tyrosine kinases: the first robin of spring. Cell 2006;127:45-8.

119. Mendoza-Naranjo A, El-Naggar A, Wai DH, Mistry P, Lazic N, et al. ERBB4 confers metastatic capacity in Ewing sarcoma. EMBO Mol Med 2013;5:1087-102.

120. Ljuslinder I, Malmer B, Isaksson-Mettävainio M, Oberg A, Henriksson R, et al. ErbB 1-4 expression alterations in primary colorectal cancers and their corresponding metastases. Anticancer Res 2009;29:1489-94.

121. Junttila TT, Sundvall M, Lundin M, Lundin J, Tanner M, et al. Cleavable ErbB4 isoform in estrogen receptor-regulated growth of breas cancer cells. Cancer Res 2005;65:1384-93.

122. Subtil A, Hémar A, Dautry-Varsat A. Rapid endocytosis of interleukin 2 receptors when clathrin-coated pit endocytosis is inhibited. J Cell Sci 1994;107:3461-8.

123. Harding C, Heuser J, Stahl P. Receptor-mediated endocytosis of transferrin and recycling of the transferrin receptor in rat reticulocytes. J Cell Biol 1983;97:329-39.

124. Lamaze C, Dujeancourt A, Baba T, Lo CG, Benmerah A, et al. Interleukin 2 receptors and detergent-resistant membrane domains define a clathrin-independent endocytic pathway. Mol Cell 2001;7:661-71.

125. Orlandi PA, Fishman PH. Filipin-dependent inhibition of cholera toxin: evidence for toxin internalization and activation through caveolae- 
like domains. J Cell Biol 1998;141:905-15.

126. Barton DP, Blanchard DK, Wells AF, Nicosia SV, Roberts WS, et al. Expression of interleukin-2 receptor alpha (IL-2R alpha) mRNA and protein in advanced epithelial ovarian cancer. Anticancer Res 1994;14:761-72.

127. Tefferi A, Vaidya R, Caramazza D, Finke C, Lasho T, et al. Circulating interleukin (IL)-8, IL-2R, IL-12, and IL-15 levels are independently prognostic in primary myelofibrosis: a comprehensive cytokine profiling study. J Clin Oncol 2011;29:1356-63.

128. Zwaagstra JC, Guimond A, O’Connor-McCourt MD. Predominant intracellular localization of the type I transforming growth factor-beta receptor and increased nuclear accumulation after growth arrest. Exp Cell Res 2000;258:121-34.

129. Forrester E, Chytil A, Bierie B, Aakre M, Gorska AE, et al. Effect of conditional knockout of the type II TGF-beta receptor gene in mammary epithelia on mammary gland development and polyomavirus middle $\mathrm{T}$ antigen induced tumor formation and metastasis. Cancer Res 2005;65:2296-302.

130. Heldin CH, Landström M, Moustakas A. Mechanism of TGF-beta signaling to growth arrest, apoptosis, and epithelial-mesenchymal transition. Curr Opin Cell Biol 2009;21:166-76.

131. Hayes S, Chawla A, Corvera S. TGF beta receptor internalization into EEA1-enriched early endosomes: role in signaling to Smad2. J Cell Biol 2002;158:1239-49.

132. Di Guglielmo GM, Le Roy C, Goodfellow AF, Wrana JL. Distinct endocytic pathways regulate TGF-beta receptor signalling and turnover. Nat Cell Biol 2003;5:410-21.

133. Stechmann B, Bai SK, Gobbo E, Lopez R, Merer G, et al. Inhibition of retrograde transport protects mice from lethal ricin challenge. Cell 2010;141:231-42.

134. Luginbuehl V, Meier N, Kovar K, Rohrer J. Intracellular drug delivery: potential usefulness of engineered Shiga toxin subunit B for targeted cancer therapy. Biotechnol Adv 2018;36:613-23

135. Lo HW, Hung MC. Nuclear EGFR signalling network in cancers: linking EGFR pathway to cell cycle progression, nitric oxide pathway and patient survival. Br J Cancer 2006;94:184-8.

136. Giri DK, Ali-Seyed M, Li LY, Lee DF, Ling P, et al. Endosomal transport of ErbB-2: mechanism for nuclear entry of the cell surface receptor. Mol Cell Biol 2005;25:11005-18.

137. Dittmann K, Mayer C, Rodemann HP. Inhibition of radiation-induced EGFR nuclear import by C225 (Cetuximab) suppresses DNA-PK activity. Radiother Oncol 2005;76:157-61.

138. Pilarczyk G, Nesnidal I, Gunkel M, Bach M, Bestvater F, et al. Localisation microscopy of breast epithelial ErbB-2 receptors and gap junctions: trafficking after gamma-irradiation, neuregulin-1beta, and trastuzumab application. Int J Mol Sci 2017; doi: 10.3390/ ijms 18020362

139. Hintersteiner M, Ambrus G, Bednenko J, Schmied M, Knox AJ, et al. Identification of a small molecule inhibitor of importin beta mediated nuclear import by confocal on-bead screening of tagged one-bead one-compound libraries. ACS Chem Biol 2010;5:967-79.

140. Cordero JB, Cozzolino M, Lu Y, Vidal M, Slatopolsky E, et al. 1,25-Dihydroxyvitamin D down-regulates cell membrane growth- and nuclear growth-promoting signals by the epidermal growth factor receptor. J Biol Chem 2002;277:38965-71. 